\title{
Responsabilidade social e perspectiva democrática: refletindo a partir do enquadramento teórico do desenvolvimento humano
}

\author{
Social responsibility and democratic perspective: \\ reflecting since the human development theoretical framework
}

\author{
Clenir Maria Moretto ${ }^{1}$ \\ ${ }^{1}$ Universidade de Passo Fundo | Faculdade de Educação | Curso de Serviço Social \\ Passo Fundo | RS | Brasil. Contato: clenir@upf.br \\ http://orcid.org/0000-0003-2200-4734

\section{Cristina Fioreze ${ }^{2}$} \\ ${ }^{2}$ Universidade de Passo Fundo | Faculdade de Educação | Curso de Serviço Social \\ Passo Fundo | RS | Brasil. Contato: fiorezecristina@gmail.com \\ http://orcid.org/0000-0002-7685-6636
}

Resumo: O presente artigo discute a responsabilidade social universitária brasileira, que passou a ser exigida como dimensão institucional com a lei do Sinaes, em 2004. Essa prerrogativa coloca às universidades o desafio de pensar sua responsabilidade e de questionar se os sujeitos que estão formando desenvolvem capacidade de reflexão, pensamento crítico e disposição para oferecer respostas à crise global e fazer enfrentamentos às injustiças econômicas e sociais. O marco legal da responsabilidade social, contudo, surge em um contexto contraditório, atravessado por processos de mercantilização do ensino superior no país. Dado o papel da instituição universidade na construção da cidadania, parte-se da compreensão de que a educação para a democracia deve ocupar lugar central nos processos formativos, assim, o artigo pretende demonstrar o alcance da perspectiva teórica do desenvolvimento humano e das capabilities, desenvolvida por Amartya Sen (2010) e Martha Nussbaum (2010), para a análise da reponsabilidade social universitária brasileira. Por meio de um processo metodológico baseado na hermenêutica, o estudo demonstra a relação entre democracia e formação na educação superior, problematiza as normativas nacionais existentes para a responsabilidade social universitária de modo contextualizado no cenário atual e reflete sobre quais seriam as responsabilidades das universidades quando o horizonte está na formação de sujeitos aptos a olhar para as realidades sociais e transformá-las. O artigo fornece, assim, uma reflexão sobre o lugar da universidade na construção da cidadania e da democracia, evidenciando que a responsabilidade social universitária, quando compreendida a partir do enquadramento teórico do desenvolvimento humano, é caminho em potencial para viabilizar processos formativos comprometidos com o bem público, o que implica movimentos de dentro para fora, que envolvem não só os estudantes, mas a comunidade acadêmica como um todo e, também, arranjos institucionais mais amplos.

Palavras-chave: Educação superior. Educação para a democracia. Responsabilidade social universitária. Desenvolvimento humano.

Abstract: This paper discusses the Brazilian university social responsibility, that became compulsory as an institutional dimension in 2004 according to Sinaes law. It brings to Brazilian universities the challenge of thinking their responsibility and of questioning if the people they are graduating develop the capacity of reflection, critical thinking and willingness to offer answers to the global crisis and face social and economic injustices. Neverthless, the social responsibility legal framework rises in a contradictory context, crossed by commodification processes of higher education in the country. Considering the role of the university in building the citizenship, we comprehend that the education to democracy should occupy central place in the formative processes. Thus, this paper intends to show the scope of the theoretical framework of human development and capabilities, developed by Amartya Sen (2010) and Martha Nussbaum (2010), to the Brazilian university social responsibility analysis. Through a methodological process based on hermeneutic, this study demonstrates the relationship between democracy and higher education, discusses social responsibility national regulations in a contextualized way in the contemporary scenario and reflects about what should be the responsibilities of the university when the horizon is in the formation of people able to both recognize and transform social realities. Therefore, the paper offers a reflection about the university role in the building of citizenship and 
democracy, demonstrating that the university social responsibility, when understood since the theoretical framework of human development, is a potential way to make feasible educational processes committed to the public good, what implies inside out movements, which refer not only to the students, but also to the academic community as a whole and broader institutional arrangements.

Key words: Higher education. Education for democracy. University social responsibility. Human development.

DOI: http://dx.doi.org/10.1590/S1414-40772019000100007

Recebido em: 13 de outubro $2017 \quad$ Aprovado em: 21 de novembro de 2018

Este é um artigo publicado em acesso aberto (Open Access) sob a licença Creative Commons Attribution Non-Commercial, que permite uso, distribuição e reprodução em qualquer meio, sem restrições desde que sem fins comerciais e que o trabalho original seja corretamente citado. https://creativecommons.org/licenses/by-nc/4.0/

\section{Introdução}

A formação humana faz parte tanto do debate científico como do político, sendo entendida como pressuposto que alimenta e legitima a construção das democracias contemporâneas, uma concepção que parte do princípio normativo da educação como um bem público (UNESCO, 2016). Um bem público, contrastando com o ganho privado, remete à ideia de bem comum e é considerado uma coisa boa para a sociedade como um todo, um bem necessário à concretização dos direitos fundamentais das pessoas (DENEULIN; TOWNSEND, 2007; UNESCO, 2016).

Embora o debate entre democracia e educação seja constituído de versões, entendemos a importância de pensar como a questão se vincula à discussão da responsabilidade das instituições de ensino superior em formar cidadãos capazes de transformar a sociedade e o meio em que vivem, o que é uma preocupação mais recentemente observada em universidades que vêm adotando uma perspectiva de engajamento social, implicadas em desconstruir a tradicional imagem de torre de marfim (TALLOIRES NETWORK, 2005). Isso, contudo, não se dá de qualquer forma e em qualquer direção e precisa ser discutido à luz dos condicionantes próprios do contexto em que se vive - um contexto pautado pelo avanço de uma concepção de educação como bem privado, do que decorrem os processos de mercantilização das instituições, a apreciação do ensino por seu valor de troca e não por seu valor intrínseco, a supervalorização da pesquisa tecnológica e útil para o mercado, entre outras características, como largamente registrado pela literatura nacional e internacional (BROWN; CARRASSO, 2013; SLAUGHTER; RHOADES; 2004; SAMPAIO, 2014; DIAS SOBRINHO, 2010).

Em se tratando de sociedades nas quais o desenvolvimento social, econômico, político e cultural fora pautado pela ausência, mesmo que temporária, da democracia institucional, este 
debate situa-se no campo das democracias jovens, o que o torna ainda mais pertinente. No Brasil, pensar a relação entre democracia e educação nos remete à premissa de que somos iniciantes no aprendizado da democracia, considerando estarmos a pouco mais de 20 anos em um regime de governo democrático. Nesse contexto, refletir sobre o que significou à sociedade brasileira (e suas instituições) ter vivido sob um governo militar autoritário é ainda aspecto importante para a formação das novas gerações.

Considerando tal contexto, esclarecemos que não é intenção, no presente estudo, operar com macro análises da realidade política ou da educação superior brasileira. Nossa proposta é, outrossim, tematizar o que acontece na micropolítica do acesso e do dia-a-dia dos estudantes no ensino superior, problematizando a responsabilidade da universidade em relação aos processos formativos por ela instaurados, considerando que os mesmos aconteçam por meio de princípios e práticas democráticas e que, por fim, produzam democracia e cidadania. Situada no âmbito da produção acadêmica sobre o tema da qualidade educativa e das normativas do ensino superior que apontam para a responsabilidade social como critério de avaliação das instituições de educação superior brasileiras, a reflexão nesse trabalho parte da premissa de Dalbosco (2011, p. 381), para o qual é impossível desenvolver uma educação de qualidade, comprometida com a formação humana dos indivíduos e o desenvolvimento democrático da sociedade, sem o aprofundamento teórico e a reflexão acerca do sentido da formação. Sendo assim, colocam-se no horizonte de nossos questionamentos os sentidos da educação democrática no ensino superior, problematizando especialmente a relação disso com a responsabilidade social da universidade.

A hermenêutica enquanto perspectiva de interpretação pressupõe a adoção de uma postura reflexiva diante de conceitos cujas fragilidades, muitas vezes, são imperceptíveis. O percurso metodológico do estudo indicou trabalharmos com a historicidade e o movimento enquanto conceitos articuladores dos saberes construídos a partir do processo hermenêutico. Tal processo constitui-se de perguntas que possibilitaram a "escuta" dos textos, cuja vigilância se deu em torno de como esses discursos se constituem, que práticas eles instituem e que verdades legitimam, considerando as complexas realidades da educação superior brasileira no âmbito das suas responsabilidades.

Isto posto, em nosso percurso iniciamos com uma problematização sobre o lugar cotidiano - de onde pensamos democracia e educação no contexto de universidades que são exigidas a serem socialmente responsáveis e, em seguida, apresentamos a dimensão normativa que implica o pensar a responsabilidade social como elemento constitutivo das universidades no Brasil, situando o processo dentro do cenário da educação superior brasileira. A partir desse 
pano de fundo, apresentamos o referencial teórico que orienta a concepção de responsabilidade social universitária que neste artigo se defende profícua para a realidade brasileira e, com isso, no próximo momento desenvolvemos seis tópicos de reflexão sobre os caminhos e desafios da responsabilidade social brasileira, à luz do enquadramento teórico proposto. Por fim, apresentamos as conclusões do artigo.

O texto fornece, assim, uma reflexão sobre o lugar da universidade na construção da cidadania e da democracia, evidenciando que a responsabilidade social universitária, quando compreendida a partir da perspectiva do desenvolvimento humano, é caminho em potencial para viabilizar processos formativos comprometidos com o bem público, o que implica movimentos de dentro para fora, que envolvem não só os estudantes, mas a comunidade acadêmica como um todo e, também, arranjos institucionais mais amplos. Colocamo-nos então, neste artigo, o desafio complexo de pensar a cidadania e a democracia como conceitos intimamente relacionados à perspectiva de formação universitária, tecendo reflexões possíveis e discutindo o lugar e o compromisso da universidade para o desenvolvimento humano e social.

\section{O que as palavras querem dizer?}

Consideremos, como ponto de partida, uma pequena história por nós vivenciada recentemente. Em uma noite de inverno no sul do Brasil, em uma universidade, discutindo os fundamentos do trabalho com políticas sociais junto a alunos concluintes vinculados a um curso de graduação da área de ciências sociais aplicadas, a professora pergunta: "como a democracia pode vir a ser um elemento importante no cotidiano de um profissional dessa área?”. Diante de um demorado silêncio, a professora refaz a pergunta, incentivando os alunos a pensarem "se seria possível sermos democráticos em nossos processos de trabalho, em nosso cotidiano profissional". Diante de mais silêncio e risos constrangidos, a professora é surpreendida por um aluno que diz: "professora, não sei, eu talvez acho que a maioria daqui não sabe o que vem a ser a democracia, para que serve a democracia”. Essa pergunta, apresentada sob a forma de constatação e/ou denúncia, inicialmente ecoou como um deserto, um semiárido ou um tipo específico de solidão, dessas que se apresentam de repente, enquanto fazemos um caminho. Posterior a esse sentimento, pensamos que poderia se tratar de uma questão linguística, alguma disjunção de termos, cujo conceito poderia não expressar o que de fato aqueles sujeitos sabem acerca da democracia. A questão crucial é que, abatidos por um profundo pesar, não tínhamos como não pensar sobre a nossa responsabilidade acerca de um processo que findava, materializado em quatro anos de formação universitária, e que talvez não tivesse tocado - 
afetado os estudantes - em questões cruciais, vitais ao que entendemos como formação crítica e humanizadora. Diante disso, nosso esforço naquele momento foi o de desencadear uma reflexão coletiva a respeito do que vem a ser a democracia, ao mesmo tempo que nos dávamos conta do difícil lugar de responder a essa questão - e a esse conceito. E enquanto abria-se o diálogo para pensar a respeito, lembrávamos, em silêncio, das palavras de Saramago, ao dizer:

Tudo se discute neste mundo, menos uma única coisa: a democracia. Ela está aí, como se fosse uma espécie de santa no altar, de quem já não se espera milagres, mas que está aí como referência. E não se repara que a democracia em que vivemos é uma democracia sequestrada, condicionada, amputada (2005, \&\#091;s. p.\&\#093;).

Estávamos nós, em lugar e tempo distantes do pensado por Saramago, testemunhando o sequestro da democracia no cotidiano de uma universidade, o que chama a atenção para um aspecto crucial a ser enfrentado no âmbito da formação, a saber, de tomarmos por óbvio ou resolvido justamente aquilo que precisa ser problematizado. Considerando esta exigência, podemos, a partir de Flickinger, refletir que:

$\& \# 091 ; \ldots \& \# 093 ;$ no próprio conceito de responsabilidade, categoria ética por excelência, reflete-se esse dever de dar respostas às perguntas colocadas pelo outro. Vemo-nos solicitados pelo outro a repensar a nossa própria postura perante ele e as dúvidas por ele articuladas. Parece-se ser essa a razão pela experiência que conseguimos aprender muito sobre nós mesmos, ao tomarmos a perspectiva desse olhar estranho e sério (2010, p. 41).

Este efeito que a pergunta do outro pode colocar a nós mesmos e à realidade da formação universitária pode reverberar nos saberes historicamente construídos e, também, no modo como pensamos as formações, por meio de um desenho de conhecimentos hierarquicamente alicerçados, supondo sujeitos que os apropriam ao mesmo tempo e lhe atribuem sentidos semelhantes. A pergunta feita à professora desafia a pensar seus pontos cegos e incompreensões, questiona sobre a sua responsabilidade em não perceber, durante o tempo de formação, a existência de lacunas como essas no processo formativo de estudantes universitários. Nesse contexto, além de provocativa, a questão convida a compreender os possíveis sentidos da democracia tendo como cenário a sociedade brasileira e, mais especificamente, a universidade brasileira. Isso porque falar de democracia no Brasil implica pensar singularidades e particularidades da realidade social, do Estado e do sentido das instituições.

Tal acontecimento e as percepções a ele inerentes fazem desse debate um fértil terreno no campo da ética. Então, se a proposta epistemológica de um docente se traduz na crença provisória de que a verdade é uma construção histórica, nosso pensamento foi de ouvir o outro, 
o que desafia não só a nossa compreensão, como também o modo como práticas formativas instauram (ou não) possibilidades de exercício da democracia. Sendo assim,

o escutar, o prestar atenção, abre-nos não apenas o acesso a um determinado conteúdo, pelo qual nos vemos desafiados a reconsiderar nossas próprias convicções e supostas certezas; ele abre, mais ainda, o acesso ao outro, à outra pessoa e seu modo de refletir e de agir, como que a um questionamento permanente que quer ser levado a sério, tanto em termos teóricos quanto em termos práticos (FLICKINGER, 2010, p. 43).

E é por meio dessa e outras escutas que questões cruciais da vida podem ser recolocadas. Pela perspectiva hermenêutica, somos exigidos a sempre a olhar para os sujeitos que "carregam" e significam os dados. É por isso que dados são sempre uma "acontecência" carregada de sentido e não simples estatísticas. Flickinger (2010), ao tratar da filosofia hermenêutica em Gadamer, coloca algumas das dificuldades do processo educacional vivido na contemporaneidade, afirmando que

$\& \# 091 ; \ldots \& \# 093 ;$ antes considerado sujeito conhecedor e dono do processo construtivo de nosso conhecimento, o homem descobre-se a si mesmo como sendo sujeito à história e, sobretudo, à linguagem. Ambas subjazem à nossa existência. Onde cada um tem de tomar consciência de si, fazendo parte da história e da linguagem que nos permitem entrar no mundo. Numa segunda argumentação a respeito, o autor refere que em vez de serem dominadas, as palavras abrem um leque infinito do que elas nos querem dizer (2010, p. 38-39).

O esforço em compreender para além das palavras e o que elas querem dizer nos leva, aqui, a olhar para este aparente lugar comum da discussão da democracia no contexto da educação superior. Lugar esse que ora parece faltar, mas não reduzido a isso, nos leva a pensar que a educação é, por si só, uma forma de compromisso social que se materializa na heterogeneidade dos projetos de universidade brasileira. Trata-se de compreender, então, que as palavras querem dizer muito mais do que podemos compreender. E nesse universo de possibilidades, a responsabilidade social da universidade situa-se como mais um lugar-conceito a decifrar.

\section{A responsabilidade (social) no contexto das universidades brasileiras}

No Brasil, desde 2004 o Ministério da Educação incluiu, por meio do SINAES, critérios de avaliação das IES (Instituições de Educação Superior) que as colocam na obrigatoriedade de desenvolver, nos cenários dos processos formativos, a responsabilidade social. A lei aponta, em síntese, a responsabilidade social universitária como tudo aquilo que a universidade faz, que venha a contribuir na inclusão social, no desenvolvimento econômico e social, na defesa do 
meio ambiente, da memória cultural, da produção artística e do patrimônio cultural (BRASIL, 2004).

Outro documento, o Instrumento de Avaliação Institucional Externa do Inep que subsidia os atos de credenciamento, recredenciamento e transformação da organização acadêmica (presencial) (INEP, 2014), tem a responsabilidade social da instituição como constitutiva de um dos seus eixos, o de Desenvolvimento Institucional. O glossário deste instrumento conceitua responsabilidade social do seguinte modo:

A responsabilidade social refere-se às ações da instituição (com ou sem parceria) que contribuem para uma sociedade mais justa e sustentável. Nesse sentido, deverão ser verificados trabalhos, ações, atividades projetos e programas desenvolvidos com e para a comunidade, objetivando a inclusão social, o desenvolvimento econômico, a melhoria da qualidade de vida, da infraestrutura urbana/local e a inovação social (INEP, 2014, p. 36).

Embora a responsabilidade social tenha sido colocada como exigência legal há mais de uma década, se observa que a definição conceitual utilizada em ambos os documentos não esclarece suficientemente a dimensão epistemológica do(s) conceito(s). Como se percebe, tratase de um conceito amplo e contraditório em si mesmo, pois poderíamos, por exemplo, nos perguntar: todo o desenvolvimento econômico guarda sintonia com uma perspectiva socialmente responsável? Ainda, observamos a fragilidade e, talvez, o caráter incipiente do conceito na medida em que percebemos orientações diferentes entre o Sinaes e o Instrumento de Avaliação quando, por exemplo, os temas da memória cultural, da produção artística e do patrimônio cultural sequer são mencionados no conceito que serve de referência para os avaliadores, embora estejam presentes na lei do Sinaes.

Vallaeys (2006), ao discutir concepções de responsabilidade social universitária, contextualiza o conceito entre a crise do saber técnico-científico, hiper-especializado (fragmentado) e uma espécie de cegueira crônica quanto aos efeitos globais decorrentes. Assim afirma o referido autor:

$\& \# 091 ; \ldots \& \# 093$; por um lado, a crise social e ecológica mundial, por outro, há de ser o ponto de partida para uma reforma universitária de responsabilização social não meramente cosmética, mas sim, produto de uma profunda reflexão sobre o significado social da produção de conhecimento e da formação profissional de líderes da ciência (2006, p. 49).

O autor refere ainda que a "Responsabilidade Social Universitária exige, a partir de uma visão holística, a articulação dos diversos setores da instituição, em um projeto de promoção social de princípios éticos e de desenvolvimento social equitativo e sustentável” (2006, p.49), objetivando a construção de saberes responsáveis e a formação de profissionais cidadãos 
igualmente responsáveis. A posição de Vallaeys (2006) possibilita pensar que a responsabilidade social universitária deveria convergir na totalidade das práticas institucionais, exigindo a construção de princípios éticos que sustentem determinada visão de desenvolvimento humano. Esses princípios éticos transversalizariam, em tese, os processos formativos, de modo a propiciar a reflexão acerca do que estamos fazendo nos espaços de formação, como estamos fazendo em termos teóricos, metodológicos e, em síntese, que projeto de sociedade estamos construindo. Esses princípios éticos também poderiam oferecer elementos para a universidade pensar que sujeitos sociais ela está formando, para qual democracia e cidadania.

Todavia, essa é uma questão que precisa ser olhada dentro de seu contexto sociopolítico e econômico, o qual condiciona o modo como se conduz a ideia de responsabilidade social - se de forma "meramente cosmética" ou com a profundidade que o tema exige - e, por conseguinte, condiciona também o modo como se pensa a formação e as práticas institucionais em sua totalidade. Dito isto, não se pode negligenciar que a emergência da responsabilidade social universitária, como exigência legal, se dá em um contexto contraditório, pois marcado por tensionamentos em direção a uma concepção de educação superior como um bem privado - que deve ser vendido e comprado no mercado como serviço comercial (WORLD BANK, 1998) e, dentro dessa lógica, atravessado por um galopante processo de expansão privada mercantil.

Olhando para este contexto, pode-se dizer que o maior responsável pela ampliação do acesso à educação superior vivenciada no país nos últimos anos foi o setor privado - entre 1995 e 2015 o total de matrículas cresceu praticamente quatro vezes, sendo 76\% delas distribuídas em IES privadas e 24\% em IES públicas (INEP, 2016) -, mais precisamente as instituições mercantis (KOPPE, 2014; DIAS SOBRINHO, 2010). Essas apresentam algumas características peculiares, tais como seu modelo de governança, realizada profissionalmente por quadros desvinculados do corpo acadêmico, seguindo um padrão empresarial e centralizado, bem como os processos de aquisição e fusão por grandes grupos educacionais de capital aberto na bolsa de valores - desde 2004 aconteceram mais de duzentas operações desse tipo (SAMPAIO, 2014).

Porém, a lógica da educação superior como um bem privado, que vem ganhando força em escala mundial, vai além dos processos de mercantilização. Nesse sentido, cabe recorrer ao conceito de capitalismo acadêmico na nova economia, cunhado por Slaughter e Rhoades (2004) para nomear a adoção de um regime de produção do conhecimento próprio da chamada economia do conhecimento. O regime do capitalismo acadêmico "requer institutos e universidades empenhados no mercado e nos comportamentos de mercado" (RHOADES; SLAUGHTER, 2009, p. 8), o que envolve medidas adotadas pelo Estado, como por exemplo, 
políticas de patentes e financiamentos, bem como ações das próprias universidades, como mudanças na gestão, em cursos ofertados, nas contratações e na concepção de pesquisa.

Mas o capitalismo acadêmico designa um processo mais amplo, que não está relacionado somente com a questão do financiamento ou com processos que são conduzidos em uma base mercantil. Certamente tais processos são centrais, mas, como argumentam Rhoades e Slaughter (2009, p. 32-33), "talvez a maior ameaça colocada pelo capitalismo acadêmico, na nova economia, seja o estar a tornar-se parte do modo como falamos e nos definimos a nós próprios". Para eles, "é precisamente isto que está a acontecer, em muitos lugares - estamos a transformar-nos em algo que não somos". Nesse sentido, não se trata apenas de uma questão relacionada a políticas nacionais ou à gestão das IES, mas é também uma questão de comportamento da comunidade acadêmica, de modo que há "também muitos membros das faculdades se inserem de forma cúmplice no processo de comercialização" (p. $35)$.

Diante disso, é possível afirmar que o contexto da educação superior, hoje, é prenhe de um ethos que, na contramão dos valores associados à responsabilidade social, toma a educação superior a partir da noção de capital humano, segundo a qual são valorizados os efeitos individuais da escolaridade e, nesse sentido, "o capital educacional, acumulado pelo trabalhador, asseguraria não só sua maior produtividade, como explicaria as diferenças individuais de oportunidades de inserção no mercado e de remuneração recebida" (BALASSIANO; SEABRA; LEMOS, 2005, p. 34). Desde essa perspectiva, fortalece-se a identidade do estudante como consumidor (SLAUGHTER; RHOADES, 2004), e isso acontece porque, quando socialmente compreendida como um bem privado, a educação deve atender "prioritariamente ao indivíduo e a seus interesses exclusivos. Neste caso, a qualidade estará determinada por significados marcadamente operacionais e instrumentais, muito mais que sociais e voltados ao bem comum" (DIAS SOBRINHO, 2010, p. 1225). Nesse sentido, o que os estudantes esperam em termos de retorno no investimento em seu capital humano passa a ser uma questão central a ser correspondida pelas IES, porque esperada pela sociedade, bem como por boa parte dos sujeitos que constroem o cotidiano da educação superior desde dentro das universidades, sejam elas públicas ou privadas.

Tendo explicitado a dimensão normativa da responsabilidade social enquanto exigência legal às universidades e, ao mesmo tempo, situado o contexto em que tal exigência se coloca, cabe agora avançar para a problematização da compreensão teórica que neste artigo - assumindo a perspectiva da educação democrática como horizonte ao compreender que educação superior 
é bem público - defendemos como profícua para fundamentar concepções e práticas de responsabilidade social universitária na realidade brasileira.

\title{
A educação democrática e a responsabilidade social das universidades: em busca de um enquadramento teórico
}

Nos filiamos, aqui, à proposição de Melanie Walker (2010), para quem as políticas que orientam o ensino superior deveriam estar ancoradas na concepção de desenvolvimento humano e das capabilities originada em Amartya Sen e Martha Nussbaum, justificando isso do seguinte modo:

\begin{abstract}
$\& \# 091 ; \ldots \& \# 093 ;$ se certos tipos de profissionais estão sendo educados em universidades orientadas para o desenvolvimento humano e social e, em particular, para desenvolver suas capacidades profissionais para o bem público ou social, isto seria uma contribuição significativa para a redução da pobreza e uma sociedade mais justa \&\#091;...\&\#093; (WALKER, 2010, p. 486, tradução nossa).
\end{abstract}

O paradigma do desenvolvimento humano é apresentado como uma alternativa ao paradigma do desenvolvimento econômico. Nesse, hegemônico nas nossas sociedades, a educação elementar é valorizada pelo ensino de atitudes básicas, alfabetização e competência matemática. Mais adiante, investe-se nas capacidades voltadas às ciências e tecnologia, mas negligenciam-se as capacidades fundamentais para a preservação das democracias (NUSSBAUM, 2010, p. 26).

Nussbaum (2010), ao identificar o excesso de tecnificação da formação contemporânea, questiona sobre quais deveriam ser as prioridades, entendendo que deveríamos estar seguros de saber reconhecer o valor da vida humana em qualquer lugar que se manifeste e nos vermos como ligados por capacidades e problemas humanos comuns com as pessoas que aparentemente estão distantes de nós. Nessa direção tem-se o paradigma do desenvolvimento humano, segundo o qual “o que importa são as oportunidades ou 'capabilities' que cada pessoa possui em certas esferas centrais que abarcam desde a vida, a saúde e a integridade física até a liberdade política, a participação política e a educação" (NUSSBAUM, 2010, p. 47, tradução nossa). Conforme a autora,

Este modelo de desenvolvimento reconhece que todas as pessoas gozam de uma dignidade humana inalienável e que esta deve ser respeitada pelas leis e as instituições. Toda nação minimamente decente deveria aceitar que seus cidadãos estão dotados de certos direitos, nessas esferas e em outras, e deveria elaborar estratégias para que superem determinados limiares de oportunidade em cada uma delas. O modelo do desenvolvimento humano supõe um compromisso com a democracia \&\#091;...\&\#093; (2010, p. 47, tradução nossa). 
Daí a compreensão de que a educação, no modelo de desenvolvimento humano, deve capacitar os cidadãos para construir e/ou preservar estes pressupostos da vida em sociedade. Torná-los aptos a viver em uma sociedade democrática requer o investimento em uma formação de caráter humanista, mais ampla que um ensino pautado na dimensão da técnica profissional (apesar do reconhecimento de sua importância), que amplie as capacidades de "desenvolver um pensamento crítico", "transcender as lealdades nacionais e enfrentar os problemas internacionais como "cidadãos do mundo" e "imaginar com compaixão as dificuldades do próximo" (2010, p. 26). Esses constituem os três pilares da cidadania democrática: o pensamento crítico, a cidadania universal e a imaginação empática (criativa).

Se os tomarmos como base de reflexão e, ao mesmo tempo, pensarmo-los no desdobramento do conceito de responsabilidade social definido por meio de indicadores de inclusão social, desenvolvimento econômico e social, meio ambiente, preservação da memória e patrimônio cultural e inovação social, teremos aí um importante ponto de reflexão sobre as realidades da formação universitária.

Dentre os principais aspectos da reflexão, ressaltamos a aposta que Nussbaum faz nas artes e humanidades como dispositivos de produção de subjetividades sintonizadas com os pilares da cidadania democrática. Para a autora, é preciso cultivar uma formação cuidadosamente desenhada em matéria de arte e humanidades, que possibilite colocar as pessoas, desde a infância, em contato com diferentes questões de etnia, gênero, experiência intelectual (2010, p. 146-147).

Se, por um lado, a arte pode fazer contraponto à lógica que superestima a ciência exata e mensurável como sinônimo de verdade, por outro Nussbaum nos possibilita pensar nas limitações das práticas que secularmente instituímos nas universidades, onde os processos recentes e gradativos de enxugamento de currículos e seu direcionamento para o mercado (SLAUGHTER; RHOADES, 2004) acabam por secundarizar disciplinas e atividades voltadas à área das humanidades e artes em geral.

Ainda refletindo sobre os pilares da cidadania democrática, uma via fértil é olhar para a capacidade de imaginação empática (e seus obstáculos) a partir da contribuição de Sennett (2012) sobre a cooperação, tema cujo desenvolvimento foi, segundo o autor, inspirado em Sen (2010) e Nussbaum (2010). Identificando neles o diagnóstico de que emerge na sociedade uma espécie de incapacidade de permitir a complexidade, Sennett argumenta que "\&\#091;...\&\#093; nossas capacidades emocionais e cognitivas se realizam insatisfatoriamente na sociedade moderna; os seres humanos são capazes de mais do que as escolas, os locais de trabalho, as organizações civis e os regimes políticos permitem" (2012, p. 43). Afirma, diante disso, que 
"nossa capacidade de cooperar é muito maior e mais complexa do que querem nossas instituições" (p. 43) e, nessa direção, abre-se à discussão acerca de como pode ser rica a experiência da interatividade com os outros e do quanto essa experiência pode ser possível.

Há, em Sen (2010), a perspectiva de que a liberdade e a individualidade sejam constitutivas do percurso ético que propicie a cooperação, mediada pelo compromisso com ideias mais ou menos emancipatórias. Pensando assim, Sennett reflete acerca de como a noção de compromisso coloca uma questão mais profunda no que diz respeito à individualidade como processo. Na visão do autor,

Compromisso significa fechamento, abrindo mão de possibilidades em nome do desejo de se concentrar em uma coisa só. Podemos, com isso, perder oportunidades. A cultura que vem emergindo exerce sobre os indivíduos uma enorme pressão para que não percam oportunidades. Em vez de fechamento, a cultura recomenda a entrega - cortar laços para sentir-se livre, especialmente os laços gerados pelo tempo (2012, p. 180).

Se o compromisso implica em fechamento e se a cultura vigente propõe a cautela na constituição de laços sociais, temos aí novos desafios para o sentido da formação acadêmica e para a compreensão do papel da universidade. Problematizando sobre as forças culturais que militam hoje em dia contra a prática da cooperação, produtoras de sujeitos reconhecidos por Sennett (2012) como “um novo tipo de caráter”, o autor argumenta que esse sujeito é constituído por meio da homogeneização do gosto, do aniquilamento das diferenças, onde há um desejo de neutralizar, domesticar o estranho e/ou o não igual. Portador de uma angústia em relação à diferença, esse sujeito conecta-se à vida social por meio de uma economia da cultura global de consumo. "Um dos resultados é o enfraquecimento do impulso de cooperar com aqueles que se mantêm teimosamente Outros" (p. 19).

Nesse sentido, pode-se inferir que Sennett corrobora com as severas preocupações apontadas do Nussbaum sobre o estado em que se encontra a educação para a cidadania nos tempos atuais, o que nos desafia a redobrar a aposta nas iniciativas e práticas educativas que mantém viva a democracia. Desafia, também, a encontrar meios de compreender, construir e avaliar tais iniciativas e práticas dentro dos cenários concretos das universidades. Nesse sentido, é producente a contribuição de Walker e McLean (2013), que trazem a perspectiva das capabilites para o âmbito da educação superior a partir do conceito de public good professionalism, pelo qual problematizam o papel da universidade na promoção do bem público. Assim, public good professionalism, segundo as autoras, foi o termo escolhido para 
vidas melhores (capabilities) e a realizações (functionings) que seus usuários tenham razões para valorizar (WALKER; MCLEAN, 2013, p. 1-2, tradução nossa).

Então, diz respeito à contribuição dada pelas universidades para uma formação perpassada pelo bem público, o que requer preparar os estudantes para fazer avançar a justiça social. Com base nesse entendimento, Walker e McLean (2013) buscaram identificar as capabilities que deveriam ser consideradas indispensáveis a profissionais orientados para o bem público e, desde aí, compreender como a educação universitária poderia contribuir para desenvolvê-las.

Assim, as autoras construíram o Public Good Professional Capabilities Index (Índice de Capabilites Profissionais para o Bem Público), uma ferramenta que parametriza a investigação sobre a formação universitária, aplicada inicialmente no contexto sul-africano, mas depois também em outras realidades, como a do Reino Unido (EAST; STROKES; WALKER, 2014). O Index parte do pressuposto de que profissionais orientados para o bem público são aqueles que: reconhecem a plena dignidade de todo ser humano; agem para a transformação social e redução da injustiça; fazem julgamentos profissionais bem informados, reflexivos e imaginativos; trabalham coletivamente para expandir as capacidades compreensivas das pessoas que vivem na pobreza (WALKER; MCLEAN, 2013). Esses quatro atributos conformam meta-functionings chave da ferramenta. O Index também contempla oito capabilities profissionais, que se constituem em objetivos educacionais que viabilizam os quatro atributos (meta-functionings), são elas: visão de mundo, relacionamento/solidariedade, resiliência, esforço social e coletivo, inteligência emocional, integridade, segurança e confiança e conhecimento e habilidades. A ferramenta apresenta, ainda, uma terceira parte, voltada para as instituições de ensino superior em si e, nesse sentido, trata de arranjos e condições educacionais necessários para que os objetivos acima mencionados sejam atingidos. Dividemse em arranjos referentes ao contexto departamental e da universidade como um todo. Os arranjos departamentais são: currículo transformador, pedagogias adequadas e cultura departamental inclusiva; já das universidades o que se espera é: cultura e ambiente institucional transformadores, crítica, deliberação/colegialidade e responsabilidade e engajamento social (WALKER; MCLEAN, 2013, p. 87).

$\mathrm{O}$ index do public good professionalism se constitui, assim, em meio para projetar, acompanhar e avaliar as iniciativas e práticas educativas dentro das universidades, fornecendo um referencial que orienta a formação universitária com base no modelo de desenvolvimento humano. Nesse sentido, constitui-se em alternativa para a materialização dos três pilares da 
cidadania democrática, o que implica, lembrando a posição de Vallaeys (2006), que pensemos a responsabilidade social universitária na totalidade das práticas institucionais.

Isso posto, cabe agora apresentar as reflexões e análises a respeito da responsabilidade social universitária no Brasil, desenvolvidas a partir do enquadramento teórico aqui proposto, de modo a identificar o alcance e a adequação do mesmo para a temática.

\section{Para pensarmos universidades socialmente responsáveis: reflexões a partir do enquadramento teórico do desenvolvimento humano e das capabilities}

Apresentamos agora, à luz do enfoque teórico delineado acima, seis reflexões sobre a responsabilidade social universitária, considerando para tanto, como aspectos centrais, a normatização existente, o atual contexto da educação superior brasileira e a relação entre educação e democracia, já trabalhados neste artigo.

Uma primeira reflexão parte da percepção de que, embora tenhamos um marco regulatório sobre a responsabilidade social universitária oferecido pelo Ministério da Educação há mais de uma década, o qual pauta que a universidade produza junto aos diferentes sujeitos o exercício formativo da responsabilidade social, a reflexão acerca de quais cidadãos pretendemos formar e qual sociedade queremos construir é ainda bastante frágil - o caráter incipiente da concepção que perpassa os documentos, antes aludido, é fator que contribui para isso. Muitas vezes, tal reflexão fica circunscrita a determinadas áreas do conhecimento, que frequentemente recebem rótulos ideologizantes. Daí um aspecto que se pode tomar como positivo nos instrumentos reguladores de práticas de responsabilidade social nas universidades brasileiras: a exigência de que a discussão da inclusão social, da realidade econômica, cultural, ambiental, seja transversalizadora dos processos formativos em todos os níveis e áreas do conhecimento. Assim, em que pese a fragilidade da reflexão sobre os fundamentos da responsabilidade social no cotidiano das IES, a existência de uma exigência legal pode ser considerada um passo inicial, a tensionar para que essa reflexão aconteça.

A segunda análise é a de que, porque não temos o acúmulo de uma reflexão mais profunda sobre os fundamentos da responsabilidade social, a tendência é a de reproduzir, na relação entre universidade e comunidade, uma concepção utilitarista historicamente arraigada, segundo a qual a universidade é uma instituição que sempre foi socialmente responsável, simplesmente porque costuma realizar algum tipo de transferência de saberes junto às populações de baixa renda - na maior parte das vezes, porém, a partir de uma perspectiva assistencialista e tuteladora, negadora dos saberes daquelas populações. Estas práticas constituíram a universidade brasileira como um lugar que supostamente dialoga com a questão 
social, sendo, ainda hoje, tomadas (equivocadamente) como parâmetro para a responsabilidade social universitária. Trata-se, assim, de uma concepção hegemônica que atravessa o senso comum universitário, a qual não se identifica com os princípios do public good professionalism. Porque ancorada numa relação verticalizada, de supremacia dos "escolarizados" sobre a população que vive na pobreza, é incapaz de desenvolver a capacidade de imaginação empática. Daí, novamente, constata-se a imprescindibilidade de problematizar, dentro das IES, os fundamentos da responsabilidade social.

Associada a isso, a terceira reflexão é atinente ao lugar ocupado pelo outro - um desafio ao fortalecimento (ou não) da cidadania democrática no contexto das universidades brasileiras. Isto é, a ideia de profissionalização para o bem público requer uma formação que reconheça o outro, sua linguagem, sua história. Provoca-nos a fazer isso de maneira que o estudante não seja o único depositário dessa intencionalidade, pois a universidade precisa fazer isso consigo mesma, talvez como condição fundamental para descobrir como tornar-se, efetivamente, socialmente responsável. Por conseguinte, colocaríamos aqui também, como importante desafio, a perspectiva de a universidade suportar a impotência de dominar o outro, na esteira do que afirma Flickinger: o "outro, na sua autenticidade própria, é, ao mesmo tempo, o estigma da nossa incapacidade e a condição de nosso autoentendimento, de nossa autocompreensão. Parece tratar-se de uma situação paradoxal, pois o outro de nós se torna o motivo para a experiência de nós mesmos" (2010, p. 39).

Daí a aposta na cooperação, como propõe Sennett (2012), moldando a quarta reflexão. Se o fortalecimento da democracia e da cidadania precisa de instituições de ensino responsáveis pelo crescimento econômico e social ético e justo, estas, por sua vez, têm de assumir o compromisso de formar sujeitos empenhados em determinados princípios éticos. Se a formação contemporânea requer a capacidade de os sujeitos sociais refletirem, relacionarem-se com as diferenças do outro e do mundo por meio de lógicas ancoradas na intersubjetividade, na empatia, na cooperação, isso há de ser construído, também, por dentro da universidade. Disso decorre a importância de pensarmos no fortalecimento da democracia como meio fértil para se instaurar o compromisso entre instituições formadoras, sujeitos em formação e sociedade. Também a pertinência de se estar alerta para a compreensão de que a democratização do acesso à universidade não significa, necessariamente, a constituição de processos democráticos que respondam aos desafios da cidadania contemporânea, como mostrou Dias Sobrinho (2010). Desse modo, assumimos que a possibilidade de constituição de experiências formativas se situa para além das exigências produtivistas e utilitaristas, o que implica rever as lógicas com que as universidades operam e se bastam no alcance de determinados padrões de qualidade. 
A quinta reflexão diz respeito às racionalidades institucionais que ganham força com o avanço de uma concepção de educação superior como bem privado, nas quais se apoia a realidade do capitalismo acadêmico. Um dos principais paradoxos do desafio de pensar a responsabilidade das instituições de educação superior brasileiras, hoje, se traduz nas questões: como formar cidadãos que promovam concepções e práticas de desenvolvimento humano e social para além do crescimento econômico, em um modelo que opera com a mercantilização da educação e que faz aumentar os índices de acesso à educação ao tempo que não promove a qualificação desse acesso? Como formar cidadãos que promovam a justiça social em modelos institucionais que vendem a educação superior como mercadoria, produzindo e sustentando a crise de legitimidade da formação democrática - crise essa polarizada entre o paradigma do desenvolvimento humano e o paradigma do desenvolvimento econômico e do capital humano? Nesse sentido, podemos entender que a lógica do capitalismo acadêmico abre espaço para que a responsabilidade social seja tomada superficialmente e utilizada - apenas e equivocadamente - como estratégia de marketing institucional.

Por fim, e na direção de enfrentamento aos obstáculos acima apontados, refletimos sobre a pertinência de se transversalizar os três pilares da cidadania democrática no cotidiano institucional, o que abrange não só os processos formativos nas atividades discentes, mas junto a todos os segmentos da comunidade acadêmica e incidindo também nos arranjos institucionais, como propõem Walker e McLean (2013). Isso pode (e deve) se efetivar de diferentes maneiras, desde que os sujeitos da universidade não abram mão da postura ética que prevê a escuta do outro, o diálogo com a estranheza e com a diferença. No âmbito das relações que se estabelecem nas instituições, especificamente, requer-se a superação da dificuldade de dialogar numa perspectiva de horizontalidade entre alunos e professores - um dos sintomas do enfraquecimento da cidadania democrática; requer-se, ainda, transcender os vícios departamentais que definem projetos de formação com base em ideais corporativistas e na lógica disciplinar que, por si só, obstaculiza o reconhecimento de outros modos de pensar e fazer, quiçá então o reconhecimento de outras culturas e das adversidades da vida contemporânea.

\section{Conclusões}

Partindo da premissa de que a pergunta pela democracia no contexto do ensino superior ressoa profundamente nas exigências normativas de se instaurar práticas de responsabilidade social universitárias, este artigo buscou demonstrar a pertinência de um olhar para a 
responsabilidade social a partir da perspectiva teórica do desenvolvimento humano e das capabilities.

Observamos, frente à argumentação aqui desenvolvida e a partir do enquadramento teórico proposto, que a responsabilidade social das universidades demanda que, ao invés de um percurso de fora para dentro - feito por muitas instituições sob a lógica da venda da imagem de uma educação que faz "o bem" -, seja, ao contrário, trilhado um caminho desde dentro, autorreflexivo e constitutivo de possibilidades de compreensão das instituições em si e do outro enquanto sujeito que vem dialogar com a realidade, com o saber, a ciência e tantos outros aspectos.

Percebemos que pensar sobre as políticas de responsabilidade social na educação superior brasileira exige não só o adensamento conceitual do termo, mas, fundamentalmente, o reconhecimento do contraponto normativo que dá sustentação à crise de legitimidade na formação democrática das instituições de ensino - situada entre o paradigma do desenvolvimento humano e o paradigma do desenvolvimento econômico. Trata-se então, nesse estudo, de reconhecer as implicações da responsabilidade social nas universidades, considerando ser a experiência democrática um caminho para sua possível efetivação.

Partindo de uma compreensão de responsabilidade social inspirada no exercício do reconhecimento do outro - como aquele que, no contexto da formação universitária, estranha a dimensão da democracia e, a partir da pergunta, nos coloca a repensar seu sentido e suas possibilidades de realização -, este exercício nos possibilita concluir que um dos principais compromissos da universidade é, mais do que entender o que as palavras querem dizer, reconhecer os sujeitos que as pronunciam como possíveis de aprender a cidadania no contexto de suas formações.

Porém, a consideração sobre a expansão do ensino superior no Brasil, em um contexto marcado pelo capitalismo acadêmico, nos possibilita pensar no risco de estarmos com universidades lotadas e ao mesmo tempo com pessoas que não produzem sentido sobre ela, para além da construção individual de suas carreiras, de seus ganhos em termos de capital humano. Aí, também, os dilemas da constituição de laços sociais e de compromissos coletivos em uma sociedade de curto prazo, o que aponta como desafio à formação a constituição de sujeitos que cooperam intersubjetivamente e respondem aos desafios dos processos excludentes que se colocam na diversidade da economia global, o que pode ser traduzido na noção de public good professionalism.

Importante dizer, finalizando o exercício de pensamento aqui desenvolvido, que esta experiência que se pretende democrática não se constitui por si só. Prescinde de humildade 
cultural, abertura ao outro, autoanálise das instituições e sensibilidade para pensar os limites da ciência e as possibilidades da arte nos processos formativos.

\section{Referências}

BALASSIANO, Moisés; SEABRA, Alexandre Alves de; LEMOS, Ana Heloisa. Escolaridade, salários e empregabilidade: tem razão a teoria do capital humano? Rev. adm. contemp., Curitiba, v. 9, n. 4, p. 31-52, 2005.

BRASIL. Lei no 10.861, de 14 de abril de 2004. Institui o Sistema Nacional de Avaliação da Educação Superior - SINAES e dá outras providências. Poder Executivo, Brasília, 2004.

BROWN, Roger; CARASSO, Helen. Everything for sale? The marketization of UK higher education. Routledge: London and New York, 2013.

DALBOSCO, Cláudio Almir. Educação natural em Rousseau: das necessidades da criança e dos cuidados do adulto. São Paulo: Cortez, 2011.

DENEULIN, Séverine; TOWNSEND, Nicholas. Public goods, global public goods and the common good. International Journal of Social Economics, Bingley, UK, v. 34, n. 1/2, p. 19-36, 2007.

DIAS SOBRINHO, José. Democratização, qualidade e crise da educação superior: faces da exclusão e limites da inclusão. Educação \& Sociedade, Campinas, v. 31, n. 113, p. 1223 $1245,2010$.

EAST, Linda; STOKES, Rebecca; WALKER, Melanie. Universities, the public good and professional education in the UK. Studies in Higher Education, Abingdon, UK, v. 39, n. 9, p. 1617-1633, 2014.

FLICKINGER, Hans-Georg. A caminho de uma pedagogia hermenêutica. Campinas: Autores Associados, 2010.

INEP. Instrumento de avaliação institucional externa do Inep que subsidia os atos de credenciamento, recredenciamento e transformação da organização acadêmica (presencial). Brasília, 2014. Disponível em: http://download.inep.gov.br/educacao_superior/ avaliacao_institucional/instrumentos/2015/instrumento_institucional_072015.pdf. Acesso em: 10 jan. 2017.

INEP. Censos da Educação Superior. Brasília, 2016. Disponível em:

http://portal.inep.gov.br/web/censo-da-educacao-superior. Acesso em: maio 2016.

KOPPE, Leonardo Renner. Instituições de Ensino Superior Privadas: organizações de ensino com fins lucrativos no Rio Grande do Sul. 2014. 256 p. Tese (Doutorado) -

Universidade Federal do Rio Grande do Sul, Porto Alegre, 2014.

NUSSBAUM, Martha. Sin fines de lucro. Buenos Aires: Discusiones, 2010.

RHOADES, Gary; SLAUGHTER, Sheila. O capitalismo acadêmico na nova economia: escolhas e desafios. In: PARASKEVA, João M. (org.). Capitalismo Acadêmico. Mangualde, Portugal: Edições Pedago, 2009.

SAMPAIO, Helena. Diversidade e diferenciação no ensino superior no Brasil: conceitos para discussão. Revista Brasileira de Ciências Sociais, São Paulo, v. 29, n. 84, p. 43-55, 2014. 
SARAMAGO, José. Quixotes hoje, utopia e política - Palestrantes José Saramago e Eduardo Galeano. In: Fórum Social Mundial, 28 de janeiro de 2005. Porto Alegre, 2005.

SEN, Amartya. Desenvolvimento como liberdade. São Paulo: Companhia das Letras, 2010.

SENNETT, Richard. Juntos: os rituais, os prazeres e a política da cooperação. Rio de Janeiro: Record, 2012.

SLAUGHTER, Sheila; RHOADES, Gary. Academic capitalism and the new economy: markets, state and higher education. Baltimore: The Johns Hopkins University Press, 2004.

TALLOIRES NETWORK. Declaration on the civic roles and social responsibilities of higher education. 2005.

UNESCO. Repensar a educação: rumo a um bem comum mundial? Brasília: UNESCO Brasil, 2016.

VALLAEYS, François. O que significa responsabilidade social universitária? Estudos, Brasília, v. 24, n. 36, p. 35-56, 2006.

WALKER, Melanie. A human development and capabilities 'prospective analysis' of global higher education policy. Journal of Education Policy, Abingdon, UK, v. 25, n. 4, p. 485$501,2010$.

WALKER, Melanie; MCLEAN, Monica. Professional education, capabilities and the public good: the role of universities in promoting human development. London: Routledge, 2013.

WORLD BANK. The financing and management of higher education: a status report on worldwide reforms. Washington: World Bank Human Development Group, 1998. 